\title{
Quantifying the treatment goals of people recently diagnosed with schizophrenia using best-worst scaling
}

This article was published in the following Dove Press journal: Patient Preference and Adherence

\author{
John FP Bridges' \\ Kathleen Beusterien ${ }^{2}$ \\ Stephan Heres ${ }^{3}$ \\ Pedro Such ${ }^{4}$ \\ Joaquín Sánchez-Covisa ${ }^{5}$ \\ Anna-Greta Nylander ${ }^{4}$ \\ Elcie Chan ${ }^{6}$ \\ Anne de Jong-Laird ${ }^{5}$ \\ 'Department of Health Policy \\ and Management, Johns Hopkins \\ Bloomberg School of Public Health, \\ Baltimore, MD, USA; ${ }^{2}$ Outcomes \\ Research Strategies in Health, \\ Washington DC, USA; ${ }^{3}$ Department \\ of Psychiatry and Psychotherapy, \\ Technische Universität München, \\ Munich, Germany; ${ }^{4}$ Global Medical \\ Affairs, H. Lundbeck A/S, Valby, \\ Denmark; ${ }^{5}$ Medical Department, \\ Otsuka Pharmaceutical Europe Ltd., \\ Wexham, UK; ${ }^{6} \mathrm{HEOR} /$ Market Access, \\ Otsuka Pharmaceutical Europe Ltd., \\ Wexham, UK
}

Objective: This study seeks to quantify the treatment goals of people recently diagnosed with schizophrenia and explore their impact on treatment plan.

Methods: People aged 18-35 years with a confirmed diagnosis of schizophrenia within the past 5 years were surveyed in the UK, Germany, and Italy. Treatment goals were assessed via a validated best-worst scaling instrument, where participants evaluated subsets of 13 possible treatment goals identified using a balanced incomplete block design. Participants identified the most and least important goals within each task. Data were also collected on current treatment and preference for daily oral versus long-acting injectable (LAI) treatment. Hierarchical Bayes was used to identify preference weights for the goals, and latent class analysis was used to identify segments of people with similar goals. The segments were compared with the current treatment and preference for oral versus LAI treatment.

Results: Across 100 participants, the average age was 26 years, $75 \%$ were male and $50 \%$ were diagnosed within 2 years ago. Overall, preferences were most favorable for reduced disease symptoms, think clearly, reduced hospitalizations, reduced anxiety, and take care of self. A total of $61 \%$ preferred oral medication and $39 \%$ LAI. Two groups were identified with different treatment goals; $50 \%$ of participants emphasized clinical goals, including reduced disease symptoms (preference weight $=19.7 \%)$, reduced hospitalizations $(15.5 \%)$, and reduced anxiety $(10.5 \%)$. The other $50 \%$ emphasized functional goals, including improved relationships with family/friends (11.4\%), increased interest in work (10.6\%), experiencing a fuller range of emotions $(8.4 \%)$, and ability to socialize (7.5\%). Those emphasizing functional goals were more likely to be on LAI ( $44 \%$ versus $26 \%$; $p=0.059$ ) and preferred LAI ( $46 \%$ versus $32 \% ; p=0.151$ ).

Conclusions: People with recent-onset schizophrenia may focus more on clinical goals or functional goals, a discussion of which may help facilitate patient engagement.

Keywords: recent-onset schizophrenia, preferences, treatment goals

\section{Introduction}

Schizophrenia is a chronic, disabling, and progressive behavioral and cognitive disease. ${ }^{1}$ Symptoms have wide-ranging impacts on a person's daily life, with substantial detrimental impacts on social, personal, vocational, and/or familial activities. ${ }^{2}$ Schizophrenia has been ranked among the top 25 leading causes of disability worldwide. ${ }^{3}$ Prevalence ranges from $0.2 \%$ to $2.6 \%$ in the European Union, ${ }^{4}$ and global estimates vary from $0.3 \%$ to $0.7 \% .{ }^{5}$ The World Health Organization estimates that direct costs of schizophrenia in Western countries range from $1.6 \%$ to $2.6 \%$ of total health care expenditures. ${ }^{5,6}$ European studies report costs of schizophrenia relapse to range from $\$ 8,665$ to $\$ 18,676$ (2015 USD) over periods of 6-12 months. $^{7}$
Correspondence: Kathleen Beusterien Outcomes Research Strategies in Health, Albemarle St NW, Washington DC, 20008, USA

Tel +l 2023628606

Email kathy.beusterien@orshealth.com
Patient Preference and Adherence 2018:12 63-70 
Following the diagnosis of the first acute psychotic episode - at the average age of 18 and 25 years in men and women, ${ }^{8}$ respectively, - treatment is recommended primarily with second-generation antipsychotics at the lower end of the standard dose range. ${ }^{9}{ }^{10}$ Mode of administration includes daily oral medication and long-acting injectable (LAI) medications, which may be prescribed once every 2 weeks, 1 month, or 3 months. ${ }^{11,12}$ Current treatments have a high rate of discontinuation. ${ }^{13}$ Reasons identified for treatment discontinuation include side effects, lack of cooperation from the patient, sudden subjective symptom improvement, forgetfulness, lack of awareness about the illness, and lack of support. ${ }^{14-16}$

The patient's perception is a critical component of many of the factors associated with treatment adherence. Accounting for such patient perceptions, consistent with a "personcentered" approach, may help in individually tailoring treatment and clinical management, and improving patient satisfaction with care and medication adherence. ${ }^{17}$ Moreover, given that the benefits of schizophrenia treatment may be wide ranging, including improvements in both physical and psychosocial facets of life, a deeper understanding of how patients may prioritize such treatment goals may help facilitate patient engagement. Such a person-centered approach is crucial in recent-onset schizophrenia because, when faced with a treatment plan that does not seem to address their individual priorities, a young person may choose to disengage. ${ }^{18}$ The earlier schizophrenia is diagnosed and treated, the better the outcome of the person and the recovery. ${ }^{19}$

Treatment outcomes identified as important among those with serious mental health conditions include enhancing relationships, self-sufficiency, well-being, employment/ hobbies, and self-improvement. ${ }^{20}$ Studies on schizophrenia have shown that improvements in these areas lead to higher quality of life. ${ }^{21}$ Ultimately, understanding the importance of outcomes among individuals with schizophrenia will help inform development of more effective clinical management strategies. ${ }^{22}$ While an increasing number of studies are examining the priorities and preferences of people diagnosed with schizophrenia, ${ }^{23-26}$ there is a paucity of literature focussing on those recently diagnosed. This study seeks to quantify the treatment goals of people recently diagnosed with schizophrenia and explore their impact on treatment plan.

\section{Methods}

People recently diagnosed with schizophrenia were recruited from 5 clinical centers across Europe (2 located in the UK, 2 in Italy, and 1 in Germany) to complete an online survey in their native language. People were included if they were $\geq 18$ and $\leq 35$ years of age; confirmed primary diagnosis of schizophrenia according to Diagnostic and Statistical Manual of Mental Disorders, Fifth Edition ${ }^{\circledR} ;<5$ years since diagnosis of schizophrenia; prescribed an anti-psychotic treatment for at least 6 months prior to the study visit; and capable of understanding and completing the questionnaire in the judgment of the investigator. They were excluded if they were experiencing psychotic symptoms at the study visit or being treated for an acute episode; having any other disorder for which the treatment took priority over treatment of schizophrenia or was likely to interfere with the treatment of schizophrenia; have had prior treatment with clozapine (indicative of severe disease) or were considered resistant to antipsychotic treatment according to the investigator's judgment; and participated in an interventional pharmacological trial in the last 12 months. Given that schizophrenia typically is first diagnosed in the young adult population, ${ }^{8}$ and a population cohort study had shown the mean age of onset to be 31.6 years, ${ }^{26,27}$ it was thought that an age range of 18-35 years would adequately capture the young adult population with a recent diagnosis.

This study followed the tenets of the Declaration of Helsinki. Identification of eligible participants was performed systematically at each clinical center, where consecutive patients attending a routine visit were assessed for eligibility. If eligible, the study aims and methods were described, and the patient was asked if he or she would like to participate. If interested in participating, the patient signed a written informed consent form, and then accessed and completed the online survey via a laptop computer at the clinical site. The study protocol was approved by the ethics review board at each participating clinical center. These included the Ethik-Kommission der Ärztekammer Berlin (Germany), the West Midlands - Coventry \& Warwickshire Research Ethics Committee (UK), the Comitato Etico Brianza (Italy), and the Comitato Etico dell'Università Sapienza (Italy). Study recruitment occurred from October 2016 to March 2017.

\section{Survey content}

Best-worst scaling (BWS) object case was chosen to assess preferences for 13 treatment goals. ${ }^{28}$ A detailed discussion of the survey development and testing for implementation in the UK, Germany, and Italy, including translation and linguistic validation into German and Italian and pre-test interviews with patients, has been published previously. ${ }^{29}$ Treatment goals included reduced disease symptoms, reduced hospitalizations, reduced anxiety, reduced sexual problems, reduced fatigue, reduced restlessness, reduced risk of weight 
gain, improved ability to think clearly, take care of self, experience a fuller range of emotions, increased interest in work/hobbies, improved communication with others, and improved relationships.

The BWS exercise incorporated a balanced incomplete block design, in which subsets comprising 4 of the 13 goals are shown, and respondents identify which is most and least important to them. ${ }^{26}$ To familiarize respondents with the goals prior to completing the BWS exercise, the instrument begins with a set of Likert scale items rating the importance of each BWS goal.

In addition, the survey includes a relatively novel direct elicitation item. ${ }^{30}$ Direct elicitation items have been used in risk-benefit studies, where the respondents are presented with a hypothetical medical intervention. They are then asked to indicate the amount of risk they would be willing to accept to achieve the benefits of the intervention or the amount of benefit they would require to accept a medical intervention with known risks. ${ }^{31}$ The current study uses a modification of this approach, presenting profiles of a standard oral and LAI treatment (ie, method and frequency of administration), and asks respondents to choose which of the 2 they most prefer, including the reason, in which respondents chose from a list of options. It also asks respondents about their willingness to try a LAI on a scale ranging from $0 \%$ ("no chance") to $100 \%$ ("definitely would try"). An example of BWS item and direct preference elicitation items are located in Figures $\mathrm{S} 1$ and $\mathrm{S} 2$.

\section{Analysis}

Descriptive analyses of the data were performed using summary statistics, including frequencies and means, for categorical and continuous data. Preference weights for each goal were computed using a Hierarchical Bayesian (HB) model, ${ }^{32}$ which accounts for potential heterogeneity in preferences across the sample. The underlying choice-probability model in HB is multinomial logit, the results of which are used to construct the joint posterior distribution of preference weights over the entire sample, including the mean and SD for each goal. Specifically, the HB estimation routine is able to stabilize the estimates for each individual by "borrowing" information from all the respondents. The preference weights are positive values, summing to $100 \%$ across the goals; these weights are ratio-scaled; that is, an outcome with a preference weight of $10 \%$ is twice as preferred as an outcome with a preference weight of 5\%.

A latent class analysis of the HB preference weights was performed, in which multinomial logistic regression was used to identify segments of people with similar goals.
Identification of the optimal latent class solution was based on Bayesian Information Criteria. ${ }^{33}$ Demographic and clinical variables were compared between segments using chisquare tests and analyses of variance, as appropriate. The statistical evaluation was performed using the software SPSS, Version 22.0 (IBM Corp., Armonk, NY, USA), as well as Sawtooth Software (Orem, UT, USA). The latent class results were validated using STATA.

There is no general basis for determining a sufficient sample size for a BWS study. ${ }^{28} \mathrm{~A}$ systematic literature review of 53 BWS studies found that sample sizes ranged from 16 to $5,026 .{ }^{34}$ Given that the plan for the current study was to analyze the data in aggregate, and all subgroup analyses would be exploratory, a sample size of 100 was considered to be sufficient for this study.

\section{Results}

A total of 100 individuals were recruited and completed the survey (43 UK; 31 Italy; 26 Germany), which took an average of 18.4 minutes. The mean age was 26 years, $75 \%$ were male, and $44 \%$ were working full- or part-time (Table 1). Approximately one-half (54\%) had undergone 1 hospitalization for schizophrenia, 33\% had been hospitalized twice, and 13\% had been hospitalized 3 or more times. Overall, $65 \%$ and $35 \%$ currently were taking a tablet and a LAI, respectively (the study participants currently were taking 13 different antipsychotic medications overall).

The BWS preference weights were most favorable for "Reduced frequency of disease symptoms (hallucinations, delusions, etc.)" (14.9\%) and least favorable for "Reduced instances of restlessness or urges to move" (4.1\%) (Figure 1). Across the 13 goals, the preference weights sum to $100 \%$. Overall, treatment goals that support a patient's daily functioning, such as the ability to think clearly and to take care of self, were rated as more important relative to reducing the risk of possible side effects of treatment. For example, "Increased ability to take care of self (being independent, able to cook, clean, etc.)" was perceived as approximately more than twice as important among participants than "Reduced risk of weight gain" (9.3\% versus $4.3 \%)$.

Preferences for oral medication or a LAI were also explored directly. In our sample, $61 \%$ preferred oral medication and 39\% a LAI. Those preferring oral medication wanted to avoid injections (44\%), were comfortable with the tablet $(23 \%)$, did not want to travel to clinic/hospital for treatment (21\%), and wanted to have control over when or how much medication is taken $(6.5 \%)$. Those preferring a LAI did not want to remember to take oral medication 
Table I Demographic and clinical characteristics

\begin{tabular}{|c|c|c|c|c|}
\hline Characteristic & All $=100$ & $\begin{array}{l}\text { Segment I: } \\
\text { Clinical } 50.0 \%\end{array}$ & $\begin{array}{l}\text { Segment 2: } \\
\text { Functional } 50.0 \%\end{array}$ & $\begin{array}{l}p \text {-value for difference } \\
\text { between segments }\end{array}$ \\
\hline Age (years), mean $\pm S D$ & $26.2 \pm 4.7$ & $26.5 \pm 4.5$ & $25.9 \pm 5.0$ & 0.572 \\
\hline Male, n (\%) & $75(75)$ & $37(74.0)$ & $38(76.0)$ & 0.817 \\
\hline Years since diagnosis, $\mathrm{n}(\%)$ & & & & 0.809 \\
\hline$<\mathrm{I}$ & $19(19.0)$ & $10(20.0)$ & $9(18.0)$ & \\
\hline Between I and 2 & $31(31.0)$ & $14(28.0)$ & $17(34.0)$ & \\
\hline$>2-5$ & $50(50.0)$ & $26(52.0)$ & $24(48.0)$ & \\
\hline Years of education, mean \pm SD & $13.2 \pm 3.4$ & $13.7 \pm 3.4$ & $12.8 \pm 3.3$ & 0.192 \\
\hline Employment, n (\%) & & & & 0.305 \\
\hline Working/volunteer & $6 I(61.0)$ & $33(66.0)$ & $28(56.0)$ & \\
\hline Not working & $39(39.0)$ & $17(34.0)$ & $22(44.0)$ & \\
\hline Living situation, $\mathrm{n}(\%)$ & & & & 0.595 \\
\hline With spouse/other family member & $7 \mid(7 \mid .0)$ & $37(74.0)$ & $34(68.0)$ & \\
\hline Alone & $20(20.0)$ & $8(16.0)$ & $12(24.0)$ & \\
\hline Supervised residential program/other & $9(9.0)$ & $5(10.0)$ & $4(8.0)$ & \\
\hline Number of hospitalizations, $\mathrm{n}(\%)$ & & & & $0.67 \mid$ \\
\hline I & $54(54.0)$ & $26(52.0)$ & $28(56.0)$ & \\
\hline 2 & $33(33.0)$ & $16(32.0)$ & $17(34.0)$ & \\
\hline$\geq 3$ & $13(13.0)$ & $8(16.0)$ & $5(10.0)$ & \\
\hline Participation in treatment decision, $\mathrm{n}(\%)$ & & & & 0.616 \\
\hline I had a lot of input & $34(34.0)$ & $17(34.0)$ & $17(34.0)$ & \\
\hline I had some input & $32(32.0)$ & $14(28.0)$ & $18(36.0)$ & \\
\hline I had no input/my family member had input & $34(34.0)$ & $19(38.0)$ & $15(30.0)$ & \\
\hline Current treatment type, $\mathrm{n}(\%)$ & & & & 0.059 \\
\hline Tablet & $65(65.0)$ & $37(74.0)$ & $28(56.0)$ & \\
\hline Long acting injectable & $35(35.0)$ & I3 (26.0) & $22(44.0)$ & \\
\hline Most preferred treatment, $\mathrm{n}(\%)$ & & & & 0.151 \\
\hline Tablet & $6 I(6 I)$ & $34(68)$ & $27(54)$ & \\
\hline Long acting injectable & 39 (39) & $16(32)$ & $23(46)$ & \\
\hline
\end{tabular}

every day $(51 \%)$, thought it was easier to follow (more convenient; $21 \%$ ), would be less worried about relapse (10\%), and wanted to avoid having to take oral medication in front of others $(5 \%)$.
Current treatment was associated with preferences, where $31(88.6 \%)$ of the 35 participants currently receiving a LAI most preferred LAI, and $57(87.7 \%)$ of the 65 patients currently receiving oral medication most preferred oral

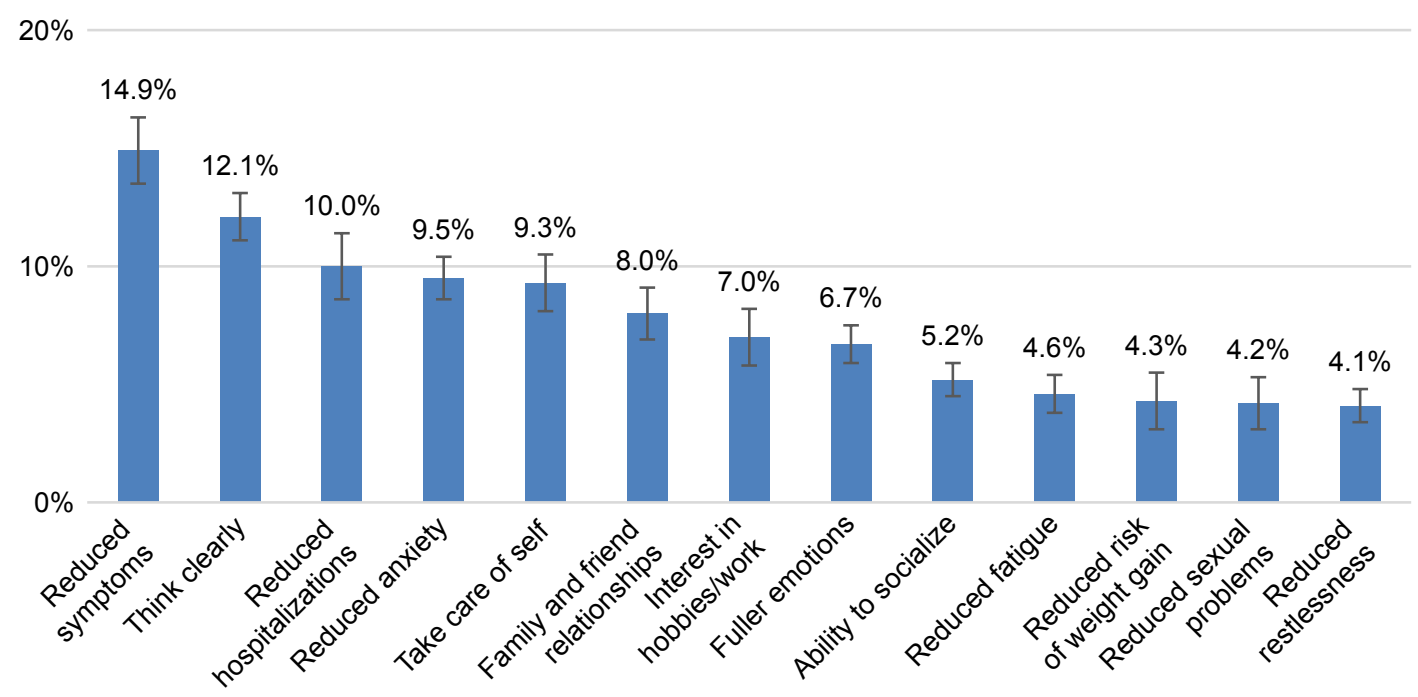

Figure I Mean preference weights for treatment goals.

Notes: Preference weights are ratio data (10\% is twice as important as $5 \%$ ); sum of preference weights is $100 \%$; $95 \%$ Cls shown. 
medication $\left(X^{2}=55.62, d f=1, p<0.001\right)$. Most patients in the sample $(\mathrm{N}=100)$ had some willingness to try a LAI, with more than half (53\%) rating their willingness as over 50\%.

\section{Latent class analysis findings}

The latent class analysis yielded 2 segments differing in prioritization of treatment goals (Table 2). A total of $50 \%$

Table 2 Treatment goal preference weights in the clinical versus functional focused segments ${ }^{\mathrm{a}}$

\begin{tabular}{|c|c|c|c|}
\hline Treatment goals & Mean, ${ }^{\mathrm{b}} \%$ & SD & $p$-value \\
\hline \multicolumn{3}{|c|}{$\begin{array}{l}\text { Reduced frequency of disease symptoms (hallucinations, } \\
\text { delusions, etc.) }\end{array}$} & $<0.001$ \\
\hline Clinical & 19.7 & 3.4 & \\
\hline Functional & 10.1 & 5.9 & \\
\hline \multicolumn{3}{|c|}{ Reduced hospitalizations due to relapse of disease symptoms } & $<0.001$ \\
\hline Clinical & 15.5 & 5.3 & \\
\hline Functional & 4.6 & 3.9 & \\
\hline \multicolumn{3}{|c|}{ Improved ability to think clearly } & 0.685 \\
\hline Clinical & 12.3 & 5.6 & \\
\hline Functional & 11.9 & 5.1 & \\
\hline \multicolumn{3}{|c|}{ Reduced anxiety (worry, stress, and agitation) } & 0.035 \\
\hline Clinical & 10.5 & 4.1 & \\
\hline Functional & 8.6 & 4.9 & \\
\hline \multicolumn{3}{|c|}{$\begin{array}{l}\text { Increased ability to take care of self (being independent, } \\
\text { able to cook, clean, etc.) }\end{array}$} & 0.065 \\
\hline Clinical & 10.4 & 5.7 & \\
\hline Functional & 8.3 & 5.5 & \\
\hline \multirow{2}{*}{\multicolumn{3}{|c|}{$\begin{array}{l}\text { Improved ability to experience a fuller range of happy } \\
\text { and sad emotions }\end{array}$}} & $<0.001$ \\
\hline & & & \\
\hline Clinical & 5.0 & 3.6 & \\
\hline Functional & 8.4 & 4.2 & \\
\hline \multicolumn{3}{|c|}{ Improved relationships with my family and friends } & $<0.001$ \\
\hline Clinical & 4.6 & 3.9 & \\
\hline Functional & 11.4 & 5.1 & \\
\hline \multicolumn{3}{|c|}{$\begin{array}{l}\text { Reduced sexual problems (sex drive, intimacy, sexual } \\
\text { functioning) }\end{array}$} & 0.927 \\
\hline Clinical & 4.3 & 5.3 & \\
\hline Functional & 4.2 & 5.4 & \\
\hline \multicolumn{3}{|c|}{ Reduced instances of restlessness or urges to move } & 0.883 \\
\hline Clinical & 4.0 & 3.8 & \\
\hline Functional & 4.2 & 3.3 & \\
\hline \multicolumn{3}{|c|}{ Reduced frequency of feeling too tired or slowed down } & 0.073 \\
\hline Clinical & 3.9 & 3.3 & \\
\hline Functional & 5.3 & 4.6 & \\
\hline \multicolumn{3}{|c|}{ Reduced risk of weight gain } & 0.235 \\
\hline Clinical & 3.6 & 5.6 & \\
\hline Functional & 5.0 & 6.1 & \\
\hline \multicolumn{3}{|c|}{ Increased interest in hobbies, studies, or work } & $<0.001$ \\
\hline Clinical & 3.5 & 3.4 & \\
\hline Functional & 10.6 & 6.2 & \\
\hline \multicolumn{3}{|c|}{ Improved ability to socialize and talk with others } & $<0.001$ \\
\hline Clinical & 2.8 & 2.2 & \\
\hline Functional & 7.5 & 3.9 & \\
\hline
\end{tabular}

Notes: a ${ }^{2}$ linical focused group $(\mathrm{N}=50)$ and functional focused group $(\mathrm{N}=50)$. ${ }^{\circ}$ Ratio data ( $10 \%$ is twice as important as $5 \%$ ); sum of preference weights is $100 \%$ within each segment. of the people $(\mathrm{n}=50)$ emphasized clinical goals, including reduced disease symptoms (weighted score of 19.7\%), reduced hospitalizations $(15.5 \%)$, and reduced anxiety $(10.5 \%)$. The other group $(\mathrm{n}=50 ; 50 \%)$ emphasized functional goals, including improved relationships with family/friends $(11.4 \%)$, increased interest in hobbies, studies, or work $(10.6 \%)$, experiencing a fuller range of emotions $(8.4 \%)$, and ability to socialize (7.5\%). Both groups valued ability to think clearly; treatment side effects generally were viewed as least important. The group emphasizing functional goals was more likely to be on a LAI ( $44 \%$ versus $26 \% ; X^{2}=3.56, d f=1$, $p=0.059)$ and preferred a LAI ( $46 \%$ versus $32 \% ; X^{2}=2.06$, $d f=1, p=0.151)$. The associations between segment membership and other demographic and clinical characteristics were not as strong (Table 1).

\section{Discussion}

This study provides new information on the treatment goals of people with recent-onset schizophrenia, specifically individuals $\leq 35$ years of age who had been diagnosed within the past 5 years. The finding in this study that reduced disease symptoms and functional impacts were most important, whereas reduced risk of treatment side effects, specifically weight gain, sexual problems, fatigue, and restlessness, were least important, is consistent with that from a previous stated preference survey in an older group of individuals with schizophrenia (mean age $=41$ years) that used a discrete choice experiment (DCE) methodology ${ }^{35}$ In addition, consistent with the finding in this study that people with LAI experience more often preferred LAI over oral medication, the patients in the DCE study, who were participants in a LAI trial, had a higher preference for a LAI over oral medication. ${ }^{35}$ Another study, involving qualitative interviews, also found that preference was higher for LAI among those with LAI experience. ${ }^{36}$

This study demonstrates that individuals recently diagnosed with schizophrenia are distributed into different segments with contrasting treatment goals: those who emphasize clinical goals, including reduced disease symptoms, reduced hospitalizations, and reduced anxiety; and those who emphasize functional goals, including increased interest in hobbies, studies, or work, improved relationships, and improved ability to socialize. It provides some evidence that these population segments are associated with treatment regimen, where those who emphasized functional goals were more likely to be taking a LAI versus oral medication. These findings provide valuable information about individuals with recent-onset schizophrenia that may enhance treatment decision-making discussions and satisfaction with care. 
The 2 segments differing in goal priorities identified in our study are consistent with those found in a previous study of individuals spanning a wider age range (mean age $=40$ years) ${ }^{37}$ Specifically, Rosenheck et al asked individuals with schizophrenia to rate the importance of 6 goals, which were similar to goals that were included in the current study. They found that respondents were distributed between 2 clusters, a "recovery cluster" (52\%) that was focused on work, relationships, and personal energy, and a "medical model cluster" (48\%) focused on improving symptoms and side effects..$^{37}$ Another study, which used a DCE methodology to assess 12 outcomes, found that respondents could be categorized into 3 segments that primarily differed based on the ability to live independently, preference to work, and having psychotic symptoms. ${ }^{38}$

The comparison of the segments with treatment regimen preferences in this study provides additional insight on goal priorities not previously examined in this population. The findings suggest that individuals emphasizing functional focused goals are more likely to choose a LAI versus oral medication. Given that the primary reasons reported for preferring LAIs were not having to remember to take a daily pill and greater convenience of LAI, the functional focused population segment may perceive that LAI treatment would accommodate involvement in work or other activities, social life, and independent living more easily than an oral medication. Indeed, a qualitative study in schizophrenia found that approximately one-half of the sample reported that injectable treatment allowed them to view their plans and aspirations more optimistically. Specifically, the most frequent considerations for the future related to finding a job, concerns for social and family lives, leisure activity, and greater autonomy.$^{36}$ It would be useful for future studies to examine the association between being functional focused and preference for LAIs in a larger sample of individuals with recent-onset schizophrenia.

A relatively novel elicitation approach was used to directly assess preferences for oral medication versus a LAI. There are no guidelines on direct elicitation, and evaluating the validity of this approach requires further study. It was found that current treatment was associated with treatment preference, but it is unclear how treatment history may also influence treatment choices. In addition, although the sample was confirmed to have a diagnosis of schizophrenia as the primary diagnosis, the participants may have had secondary diagnoses of other mental health conditions, which were not identified, that may have influenced the prediction of segment membership and treatment regimen preferences. Finally, this study did not measure nonadherence to treatment, which may influence perceptions of treatment goals. Further research on this association would be useful. Given the length of the survey, it may not be practically replicable in a clinical setting for routine administration. However, as the findings indicate that people with schizophrenia are motivated by either more clinically focused goals or by functional-focused goals, it may be enough to simply ask patients which they care about more.

\section{Conclusions}

People with recent-onset schizophrenia, specifically individuals $\leq 35$ years of age who have been diagnosed within the past 5 years, recognize the importance of disease symptoms and their substantial impacts on every day activities and relationships. With respect to preferences for treatment goals, they are no different than the average individual with schizophrenia. Consistent with the literature, we find that people with recent-onset schizophrenia are distributed between different segments focusing on clinical goals versus functional goals. Thus, clinical inquiry should seek to identify in which segment a patient may belong. Knowledge of the patient's segment may be a key factor informing the optimal treatment regimen for a given patient, and discussion of LAIs as well as oral medication should be highlighted early on in the course of illness. Discussing the goals that a patient cares about most will help facilitate patient engagement and likely increase satisfaction with care.

\section{Acknowledgments}

The authors gratefully acknowledge the participating clinical centers: Ospedale San Gerardo di Monza (Italy) with Principal Investigator (PI) Prof Massimo Clerici, Azienda Ospedaliera "Sant'Andrea"di Roma (Italy) with PI Prof Paolo Girardi, Vivantes Klinikum am Urban - Berlin (Germany) with PI Dr Karolina Leopold, Cambridgeshire and Peterborough Foundation Trust (UK) with PI Prof Jesús Pérez and Leicestershire Partnership NHS Trust (UK) with PI Dr Debasis Das. We also thank Kaitlan Amos, BS, for her assistance in survey programming and statistical analysis. An abstract of this paper was presented at the 2017 30th European College of Neuropsychopharmacology (ECNP) Congress, 2-5 September 2017, as a poster presentation. This work was supported by Otsuka Pharmaceutical Europe Ltd. and H. Lundbeck A/S.

\section{Disclosure}

KB provides consulting services to Otsuka Pharmaceutical Europe Ltd and H. Lundbeck A/S. JFPB advises ORS Health and has received travel expenses from $\mathrm{H}$. Lundbeck $\mathrm{A} / \mathrm{S} / \mathrm{Otsuka}$ Pharmaceutical Europe Ltd. SH has received speaker honoraria and/or participated in clinical trials supported by Janssen-Cilag, 
Eli Lilly, Sanofi-Aventis, Otsuka Pharmaceutical Europe Ltd, H. Lundbeck A/S and Johnson \& Johnson, Pfizer, BristolMyers-Squibb, AstraZeneca, Novartis, Servier, Pierre Fabre, Organon, Roche and Merck, Teva, and Janssen. PS and AGN are employees of H. Lundbeck A/S. JSC, EC, and AJL are employees of Otsuka Pharmaceutical Europe Ltd. The authors report no other conflicts of interest in this work.

\section{References}

1. DeLisi LE. The concept of progressive brain change in schizophrenia: implications for understanding schizophrenia. Schizophr Bull. 2008; 34(2):312-321.

2. Swain SP, Behura SS, Dash MK, Nayak AK, Patil SS. The influence of psychosocial dysfunctions in chronic schizophrenia patients in remission: a hospital-based study. Indian J Psychol Med. 2017;39(2): $157-163$.

3. Vos T, Barber RM, Bell B, et al; Global Burden of Disease Study 2013 Collaborators. Global, regional, and national incidence, prevalence, and years lived with disability for 301 acute and chronic diseases and injuries in 188 countries, 1990-2013: a systematic analysis for the global burden of disease study 2013. Lancet. 2015;386(9995):743-800.

4. Wittchen HU, Jacobi F, Rehm J, et al. The size and burden of mental disorders and other disorders of the brain in Europe 2010. Eur Neuropsychopharmacol. 2011;21(9):655-679.

5. Chong HY, Teoh SL, Wu DB, Kotirum S, Chiou CF, Chayakunapruk N. Global economic burden of schizophrenia: a systematic review. Neuropsychiatr Dis Treat. 2016;12:357-373.

6. Barbato A. Schizophrenia and Public Health. Geneva: World Health Organization; 1998.

7. Pennington $\mathrm{M}, \mathrm{McC}$ rone $\mathrm{P}$. The cost of relapse in schizophrenia. Pharmacoeconomics. Epub 2017 May 22.

8. Sham PC, MacLean CJ, Kendler KS. A typological model of schizophrenia based on age of onset, sex, and familial morbidity. Acta Psychiatr Scand. 1994;89(2):135-141.

9. NICE, 2014 [Internet]: Psychosis and schizophrenia in adults: The NICE guideline on treatment and management, updated edition; 2014 Available from: http://www.ncbi.nlm.nih.gov/books/NBK248060/pdf/ Bookshelf_NBK248060.pdf. Accessed July 10, 2017.

10. Hasan A, Falkai P, Wobrock T, et al; World Federation of Societies of Biological Psychiatry (WFSBP) Task Force on Treatment Guidelines for Schizophrenia. World federation of societies of biological psychiatry (WFSBP) guidelines for biological treatment of schizophrenia, part 1: update 2012 on the acute treatment of schizophrenia and the management of treatment resistance. World J Biol Psychiatry. 2012;13(5):318-378.

11. Kim E, Berwaerts J, Turkoz I, Gopal S. Time to schizophrenia relapse in relapse prevention studies of antipsychotics developed for administration daily, once monthly or every three months. Aust NZJ Psychiat. 2016;50(Suppl 1):166.

12. Decuypere F, Sermon J, Geerts P, et al. Treatment continuation of four long-acting antipsychotic medications in the Netherlands and Belgium: a retrospective database study. PLoS One. 2017;12(6):e0179049.

13. Ochoa S, López-Carrilero R. Early psychological interventions for psychosis. World J Psychiatry. 2015;5(4):362-365.

14. Moritz S, Hünsche A, Lincoln TM. Nonadherence to antipsychotics: the role of positive attitudes towards positive symptoms. Eur Neuropsychopharmacol. 2014;24(11):1745-1752.

15. Taylor DM, Sparshatt A, O’Hagan M, Dzahini O. Paliperidone palmitate: factors predicting continuation with treatment at 2 years. Eur Neuropsychopharmacol. 2016;26(12):2011-2017.

16. Reddy KS, Thirthalli J, Kumar CN, et al. Treatment discontinuation in schizophrenia: a qualitative exploration from a rural South Indian community. J Neurosci Rural Pract. 2017;8(2):254-260.

17. Stanghellini G, Bolton D, Fulford WKM. Person-centered psychopathology of schizophrenia: building on Karl Jaspers' Understanding of patient's attitude toward his illness. Schizophr Bull. 2013;39(2):287-294.
18. Lincoln C, McGorry PD. Pathways to care in early psychosis: clinical and consumer perspectives. In: McGorry PD, Jackson HJ, editors. The Recognition and Management of Early Psychosis: A Preventive Approach. Cambridge, UK: Cambridge University Press; 2004:51-80.

19. Karson C, Duffy RA, Eramo A, Nylander AG, Offord SJ. Long-term outcomes of antipsychotic treatment in patients with first-episode schizophrenia: a systematic review. Neuropsychiatr Dis Treat. 2016; 12:57-67.

20. Deegan PE, Carpenter-Song E, Drake RE, Naslund JA, Luciano A, Hutchison SL. Enhancing clients' communication regarding goals for using psychiatric medications. Psychiatr Serv. 2017;68(8):771-775.

21. Vrbova K, Prasko J, Ociskova M, et al. Quality of life, self-stigma, and hope in schizophrenia spectrum disorders: across-sectional study. Neuropsychiatr Dis Treat. 2017;13:567-576.

22. Forray C, Buller R. Challenges and opportunities for the development of new antipsychotic drugs. Biochem Pharmacol. 2017;143:10-24.

23. Kinter ET, Schmeding A, Rudolph I, dosReis S, Bridges J. Identifying patient-relevant endpoints among individuals with schizophrenia: an application of patient centered HTA. Int J Tech Assess Health Care. 2009;25(1):35-41.

24. Levitan B, Markowitz M, Mohamed AF, et al. Patients' preferences related to benefits, risks, and formulations of schizophrenia treatment. Psychiatr Serv. 2015;66(7):719-726.

25. Bridges JF, Slawik L, Schmeding A, Reimer J, Naber D, Kuhnigk O. A test of concordance between patient and psychiatrist valuations of multiple treatment goals for schizophrenia. Health Expect. 2013;16(2):164-176.

26. Eiring Ø, Landmark BF, Aas E, Salkeld G, Nylenna M, Nytrøen K. What matters to patients? A systematic review of preferences for medication-associated outcomes in mental disorders. BMJ Open. 2015; 5(4):e007848.

27. Svensson AC, Lichtenstein P, Sandin S, Öberg S, Sullivan PF, Hultman CM. Familial aggregation of schizophrenia: the moderating effect of age at onset, parental immigration, paternal age and season of birth. Scand J Public Health. 2012;40(1):43-50.

28. Louviere J, Flynn TN, Marley AAJ. Best-Worst Scaling: Theory, Methods, and Applications. Cambridge, UK: Cambridge University Press; 2015.

29. Beusterien K, Chan E, Such P, et al. Development of a stated-preference instrument to prioritize treatment goals in recent onset schizophrenia. Curr Med Res Opin. 2017;33(12):2129-2136.

30. Beusterien K, Kennelly MJ, Bridges JF, Amos K, Williams MJ, Vasavada S. Use of best-worst scaling to assess patient perceptions of treatments for refractory overactive bladder. Neurourol Urodyn. 2016; 35(8):1028-1033.

31. Brett Hauber A, Fairchild AO, Reed Johnson F. Quantifying benefit-risk preferences for medical interventions: an overview of a growing empirical literature. Appl Health Econ Health Policy. 2013;11(4):319-329.

32. Hauber AB, González JM, Groothuis-Oudshoorn CG, et al. Statistical methods for the analysis of discrete choice experiments: a report of the ISPOR Conjoint Analysis Good Research Practices Task Force. Value Health. 2016;19(4):300-315.

33. Dziak JJ, Coffman DL, Lanza ST, Li R. Sensitivity and specificity of information criteria. PeerJ. 2015;3:e1350.

34. Muhlbacher AC, Kaczynski A, Zweifel P, Johnson FR. Experimental measurement of preferences in health and healthcare using best-worst scaling: an overview. Health Econ Rev. 2016;6(1):2.

35. Katz EG, Hauber B, Gopal S, et al. Physician and patient benefit-risk preferences from two randomized long-acting injectable antipsychotic trials. Patient Prefer Adherence. 2016;10:2127-2139.

36. Caroli F, Raymondet P, Izard I, Plas J, Gall B, Delgado A. Opinions of French patients with schizophrenia regarding injectable medication. Patient Prefer Adherence. 2011;5:165-171.

37. Rosenheck R, Stroup S, Keefe RS, et al. Measuring outcome priorities and preferences in people with schizophrenia. Br J Psychiatry. 2005; 187:529-536.

38. Zipursky RB, Cunningham CE, Stewart B, Rimas H, Cole E, Vaz SM. Characterizing outcome preferences in patients with psychotic disorders: a discrete choice experiment. Schizophr Res. 2017;1875:107-113. 


\section{Supplementary materials}

Considering only these four goals, which one is the Most important and which is Least important to you?

\begin{tabular}{|c|l|c|}
\hline $\begin{array}{c}\text { Most } \\
\text { important }\end{array}$ & & $\begin{array}{c}\text { Least } \\
\text { important }\end{array}$ \\
\hline$\circ$ & Reduced frequency of disease symptoms (hallucinations, delusions, etc.) & $\circ$ \\
\hline$\circ$ & Improved ability to experience a fuller range of happy and sad emotions & $\circ$ \\
\hline$\circ$ & Improved ability to think clearly & $\circ$ \\
\hline$\circ$ & Reduced instances of restlessness or urges to move & $\circ$ \\
\hline
\end{tabular}

Figure SI BWS item.

Abbreviation: BWS, best-worst scaling.

Please imagine that your doctor has recommended that you start a new treatment, and has suggested either Treatment A or Treatment B. Assuming there are no other differences between Treatment A and Treatment B than those shown below, which would you choose?

\begin{tabular}{|l|l|}
\hline Treatment A & Treatment B \\
\hline $\begin{array}{l}\text { - An oral tablet every day } \\
\text { - Your responsibility is to remember to take } \\
\text { the tablet every day }\end{array}$ & $\begin{array}{l}\text { - An injection in the arm or buttock once a month } \\
\text { - Your responsibility is to keep your appointment to visit } \\
\text { the clinic once a month } \\
\text { - If you forgot to take, or deliberately skip } \\
\text { your daily dose, the likelihood of relapse } \\
\text { increases }\end{array}$ \\
$\begin{array}{l}\text { If you do not keep your appointment to visit the clinic } \\
\text { for your monthly injection, the likelihood of relapse } \\
\text { increases }\end{array}$ \\
\hline
\end{tabular}

- I would choose Treatment A

- I would choose Treatment B

Please indicate the main reason for your preference for the tablet instead of the injection (please choose one).

- Avoiding injections

- Comfortable with tablet

- Not having to go to the clinic or hospital for treatment

- Have control over when treatment is taken

- Have control over how much treatment is taken

- Other

Please indicate the main reason for your preference for injection instead of the tablet (please choose one).

- Not having to remember to take a tablet every day

- Easier to follow (more convenient)

- Needing to take the table at the same time every day or with a meal

- Less worried about having a relapse

- Avoiding having to take a tablet in front of others

o Other

Please imagine that your doctor has recommended that you start a new treatment. One of the options made available to you is a once monthly injection, administered by a nurse at a clinic. How likely would you be willing to take a once-monthly injection on a scale from $0 \%$ (No chance) to $100 \%$ (Yes definitely would try it)?

Figure S2 Direct preference elicitation items.

Patient Preference and Adherence

\section{Dovepress}

\section{Publish your work in this journal}

Patient Preference and Adherence is an international, peer-reviewed, open access journal that focuses on the growing importance of patient preference and adherence throughout the therapeutic continuum. Patient satisfaction, acceptability, quality of life, compliance, persistence and their role in developing new therapeutic modalities and compounds to optimize clinical outcomes for existing disease states are major areas of interest for the journal. This journal has been accepted for indexing on PubMed Central. The manuscript management system is completely online and includes a very quick and fair peer-review system, which is all easy to use. Visit http://www. dovepress.com/testimonials.php to read real quotes from published authors. 